\title{
A MENORÁ E A ÁRVORE DA VIDA
}

\section{EDGARD LEITE ${ }^{1}$}

Resumo: A menorá, o candelabro de sete braços, um objeto ritual do Templo de Jerusalém, adquiriu grande relevância na literatura bíblica. Primeiro como representação do cosmo, tanto do mundo visível quanto do invisível. Segundo, como árvore da vida, e representação de Deus e da vida eterna. E por fim, no desenvolvimento da Kabalá, como representação da árvore sefirótica.

Keywords: Menorá, Judaísmo, Árvore da Vida.

1.

O corpo literário judaico é vasto e antigo. Tem servido, há séculos, de base para uma série de reflexões religiosas e filosóficas.

1 Doutor em História, Academia Brasileira de Filosofia, Universidade do Estado do Rio de Janeiro, Universidade Federal do Estado do Rio de Janeiro. edleiteneto@yahoo. com.br.
O Pentateuco, ou Torá, a Lei, é o documento que os judeus consideraram como o seu texto mais sagrado, atribuído pela tradição a Moisés. Nele está presente o essencial das preocupações legais e religiosas judaicas. Mas os seus temas ecoam de forma diversa em outros conjuntos literários bíblicos e exegéticos. Os demais textos bíblicos hebraicos, o conjunto do Talmude, o Zohar e a literatura rabínica, de uma forma geral, guardam uma coerência interna. Usualmente estão centrados em preocupações comuns, como o tema da redenção humana.

Ao longo do tempo, os que se dedicaram à elaboração e interpretação dos textos sagrados, normalmente entenderam que toda divagação, transitória e aparente, remetia, no entanto, a uma dimensão que não era temporal, mas sim eterna. Para os narradores bíblicos e da tradição judaica, a permanente atualização do Eterno atestava sua existência. E confirmava a transitoriedade das coisas do mundo.

Assim se passa com o entendimento da menorá, o candelabro de sete braços. É este um dos temas recorrentes da literatura judaica e cuja 
permanência como objeto de visão (espiritual ou intelectual) demonstra a crença contínua no seu caráter transcendental, ou arquetípico. Isto é instância espiritual e elemento referencial.

\section{2.}

Segundo o Livro do Êxodo,

[A] glória de Deus pousou sobre o monte Sinai, e a nuvem o cobriu durante seis dias. No sétimo dia, Deus chamou Moisés do meio da nuvem. $O$ aspecto da glória de Deus era, aos olhos dos israelitas, como um fogo consumidor no cimo da montanha (Ex. 24. 16-18).

A narrativa explica que Deus se dirigiu a Moisés dizendo: "faze-me um santuário, para que eu possa habitar no meio deles. Farás tudo conforme o modelo da habitação e o modelo da sua mobília que irei te mostrar" (Ex. 25. 8-9). Entre as mobílias a serem colocadas no santuário estavam a Arca da Aliança, o propiciatório com os querubins e a mesa dos pães da oblação. E um candelabro de sete braços, a menorá:

Farás um candelabro de ouro puro ... seis braços sairão de seus lados: três braços do candelabro de um lado e três braços do candelabro do outro lado... tudo se fará com um bloco de ouro batido. Far-lhe-ás também sete lâmpadas. As lâmpadas serão elevadas de tal modo que alumiem defronte dele ... vê, pois, e faze tudo conforme o modelo que te foi mostrado sobre a montanha (Ex. 25. 31-40)

O texto também estabelece a presença "de cálices [ou ornamentos] com formato de flor de amêndoa com botão e flor" três em cada braço do candelabro, quatro no seu eixo central. Sendo que das do eixo central três estariam dispostas antes de cada braço (Ex. 25. 31-40). Era para ser acesa utilizando-se "azeite puro de olivas esmagadas ... para que nele haja uma chama permanente" (Lev, 24, 3), ato a ser realizado pelo Sumo-sacerdote, em pessoa (Ex, 30, 7-8).
M. Haran assim reconstruiu a menorá (apud HACHLILI, 2001, p. 29):

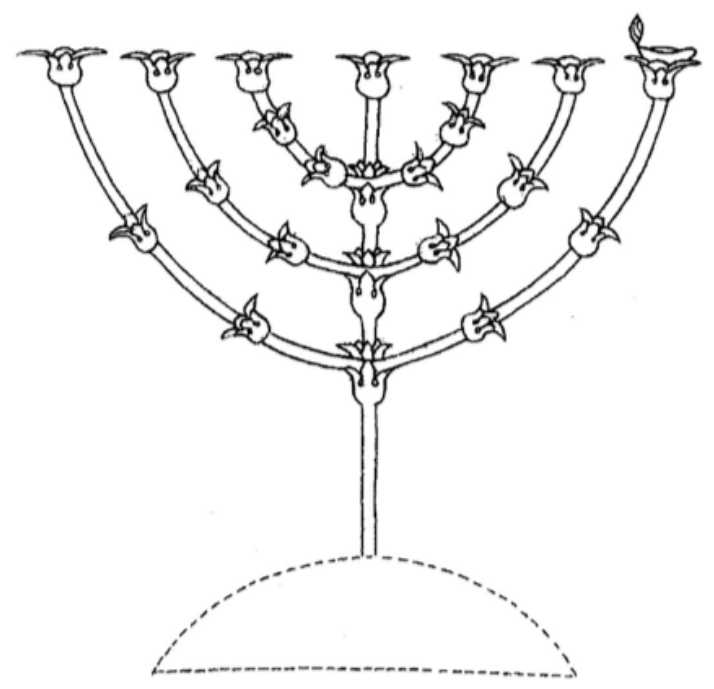

A relevância desse objeto é evidente pela referência contínua à sua presença e ao seu papel, em diversos momentos na literatura bíblica.

Séculos depois da revelação do Sinai, por volta de 970 a.C., quando Davi instruiu Salomão sobre o templo a ser construído, deixou separado "os lingotes destinados aos candelabros de ouro e as suas lâmpadas, o ouro em lingotes destinado a cada candelabro e a suas lâmpadas" (1Cr. 28.15). De fato, no Templo construído por Salomão é dito que existiam dez, e não apenas um, candelabros "de ouro puríssimo" (1Rs. 7.49) feitos "segundo o modelo prescrito" (2Cr.4.7). É também anotado que tais candelabros, junto com outros objetos de ouro, foram quebrados por Nabucodonosor quando do saque de Jerusalém, em 597 a.C. (2Rs. 24.13) (Jr. 52.18).

No Segundo Templo restaurado, após 520 a.C, ao que tudo indica, havia apenas uma menorá. Ben Sira, no Eclesiástico, parece mencioná-la, ao dizer que "uma lâmpada reluzindo sobre o candelabro sagrado, assim é a beleza de seu rosto em corpo bem acabado" (Eclo. 26.17).

Antíoco Epiphanes, o soberano sírio, quando "entrou com arrogância no santuário", em 169 a.C., "tomou para si o altar de ouro, o candelabro com todos seus acessórios" (1Mc. 1.21). Quando Judas Macabeu, logo depois, recobrou o Templo 
para o controle dos judeus, ordenou a fabricação de "novos utensílios sagrados" e levou para "dentro do Templo o candelabro, o altar dos perfumes e a mesa" (1Mc. 4.49). É esse candelabro, provavelmente, que aparece no Arco de Tito, como um dos troféus levados de Jerusalém pelas forcas romanas vitoriosas, após a destruição do Templo, em 70 d.C.

A literatura bíblica entende que, no Sinai, deu-se a determinação divina de construção da menorá. Mas a transformação desse desenho sagrado, oriundo da mente de Deus, em objeto, não foi ato esgotado na primeira menorá. Ao longo dos séculos seguintes muitas menorot foram feitas, com base nesse projeto divino, o que realça, acima de tudo, o caráter abstrato e conceitual do plano. Assim, quando Ben Sira compara o rosto da mulher à chama do "candelabro sagrado", entende que existe um plano superior, no traço da menorá, que possui os atributos da beleza.

O que é importante, na menorá, é assim, o seu projeto, o seu desenho original, e, menos, as menorot concretas. Ou seja, o que é levado em conta na longa trajetória da literatura bíblica é a consideração à intenção de Deus ao concebê-la. Bem como a reflexão contínua sobre tal intenção e seu significado no âmbito geral das relações entre o ser humano e Deus.

\section{3.}

Os sábios judeus criavam ou coletavam, na antiguidade, estudos e interpretações, ou midrashim, para as passagens bíblicas. Nestas há, muitas vezes, a presença de elementos lendários, preservados pela tradição, e que eram tidos por divinamente inspirados. Seu papel era esclarecer detalhes e eventos bíblicos. Num desses antigos midrashim é explicada a conexão maior entre a criação do mundo e a construção do Templo e como nesse processo se podia entender a menorá:

"No primeiro dia da criação", teria dito Deus aos anjos, "eu farei os céus e os colocarei em seus lugares, assim Israel erguerá o tabernáculo, como o local onde repousará minha glória. No segundo dia, eu colocarei uma divisão entre as águas terrestres e as celestiais, assim, será erguido um véu no Tabernáculo para separar o local sagrado do mais sagrado. No terceiro dia eu farei a terra produzir gramas e vegetais, assim ele, Israel, comerá vegetais na primeira noite da Páscoa e preparará pães em minha honra. No quarto dia, eu farei os luminários do céu, assim, ele, Israel, fará um candelabro de ouro para mim" (apud GINZBERG, 2003, p. 48).

O filósofo judeu Philo de Alexandria (25 a.C- 50 d.C), corrobou essa explicação mítica, inspirado pelos elementos da filosofia grega, afirmando que

[O]s seis braços, três de cada lado, saindo de um eixo central, sustentam sete lâmpadas, símbolos daquilo que os homens de ciência chamam planetas. Pois o sol, como o eixo central do candelabro, ocupa o quarto lugar no meio dos seus e dá luz aos três acima e aos três abaixo, dá o tom de harmonia a um instrumento musical divino (PHILO, Moses, II.XXI.101).

A significação cósmica da menorá era, assim, amplamente estabelecida. Continha ela um modelo cosmológico. Era como se através dela se entrasse em contato com uma representação abstrata, e arquetípica, modelar, do mundo.

Outro midrash sustentou que havia dez candelabros no Templo de Salomão, porque:

[C]orrespondia ao número das leis reveladas no Sinai, e cada um desses candelabros tinha sete lâmpadas, setenta, no total, que correspondia às setenta nações do mundo. Pois enquanto essas lâmpadas queimassem, o poder dessas nações estaria sendo colocado em cheque, mas no dia em que essas lâmpadas fossem extintas, o poder das nações cresceria (apud GINZBERG, 2003, p. 645)

Parece assim que a menorá, como desenho de Deus, era acima de tudo uma representação do mundo sob a forma de um objeto ritual. Possuía relação clara com os eventos do quarto dia da criação, com a estrutura geral do cosmo, sintetizando suas dinâmicas e realidades.

A menorá também sintetizava realidades históricas e temporais do mundo, relacionadas igualmente a uma lógica estruturante do universo criado. A humanidade estava contida, ou referenciada, de forma espiritual, nos candelabros do templo, que se 
constituíam, assim, em representações simbólicas também das sociedades humanas. Como anotou Maurice Schmidt, além do mais, existia na menorá a enigmática simetria visível nas duas metades espelhadas "separadas por uma simples linha divisória" que representam o pacto entre os homens e Deus. Elemento central da literatura bíblica. E, aponta Schimdt, a menorá também expressava a realidade de elementos mais gerais existentes no mundo, como a natureza simétrica do corpo humano e dos vertebrados (SCHIMDT, 2009, p. 140). Além do mais, sete eram também os dias da criação e sete os dias em que a Glória de Deus esteve sobre o Monte Sinai.

Ao perceber, ver, entender e acender a menorá, o sacerdote entrava em contato, portanto, com uma misteriosa e infinitamente poderosa representação do cosmo, que não era estranha ao mistério que representava, mas parte integrante dele.

4.

Como anotamos, a menorá tinha, como ornamentos, botões e flores de amêndoas. No livro de Jeremias está escrito:

Foi-me dirigida a palavra de Deus nos seguintes termos: "O que estás vendo, Jeremias?" Eu respondi: "Vejo um ramo de amendoeira". Então Deus me disse: "Viste bem, porque eu estou vigiando sobre a minha palavra, para realizá-la" (Jer. 1.11-12).

O jogo de palavras entre shaqed, "amendoeira" e "shoqued" "vigilante", assinala a correspondência entre uma representação simbólica de origem vegetal e a presença de Deus. "Lembra-te do teu criador", está escrito no Eclesiastes, "quando a amendoeira está em flor" (Ec. 12.5). Devemos também anotar que a termo bíblico luz (amêndoa, Gen. 35.37) designa, na tradição rabínica, o osso em formato de amêndoa, provavelmente o cóccix, a partir do qual acreditavam os rabinos que iria ocorrer a ressurreição dos mortos (RABINOWITZ, 2007, p. 279). Isto é, na amêndoa, osso humano, enquanto fruto de uma abstrata árvore sagrada, ou seja, Deus, estava sediada, de alguma maneira, a alma eterna.
Luz era também um povoamento, identificada com a cidade de Beth-El, tomada pelos israelitas, no tempo dos Juízes, e na qual, segundo lendas judaicas antigas, o anjo da morte não tinha poder. Os israelitas teriam entrado na cidade através de uma caverna, acessível através do oco de uma amendoeira (GINZBERG, 2003, p. 860). Foi construída, assim, uma clara associação entre Deus, enquanto fonte da vida, e a amendoeira.

Considerando tais elementos, Carol Meyers entendeu que a base do desenho da menorá era de fato uma matriz de natureza vegetal, mas sugeriu que a peça possuía, do ponto de vista estilístico, alguma inspiração egípcia, ecoando os motivos vegetais das colunas do Egito e seus juncos estilizados (MEYERS, 1992). Pode ser, mas o substrato, a amendoeira, é uma árvore nativa da Judéia.

O tema, de articulação simbólica entre Deus e árvores ou plantas, é presente na Bíblia. No livro de Zacarias, o profeta persiste na associação entre o candelabro e a representação vegetal:

Ele me disse: 'que vês?' E eu disse: 'vejo um lampadário todo de ouro com um reservatório em sua parte superior; sete lâmpadas estão sobre ele e sete canais para as lâmpadas que estão em sua parte superior. E junto dele estão duas oliveiras, uma à direita do reservatório, e outra à sua esquerda'. Então eu perguntei ao anjo que falava comigo: 'o que significam estas coisas, meu Senhor?' (...) e ele respondeu-me (...): 'Estes sete são os olhos de Deus, que percorrem toda a terra (...) estes [as oliveiras] são os dois Ungidos que estão de pé diante do Senhor de toda a terra' (Zc 4.1-14)

A dúvida se o lampadário de Zacarias é de fato uma menorá, isto é, se possui realmente sete braços, é estabelecida (HACHLILI, 2001, p. 25), mas nos parece menor. A associação entre as sete chamas e as árvores, neste caso, é evidente, e reforça a força da identificação entre a menorá e os temas vegetais.

Tendo em vista esses elementos, Leon Yarden sugeriu, a nosso ver acertadamente, que a menorá era, em verdade, a estilização de uma amendoeira (YARDEN, 1991, p. 39) e que evocava também o arquétipo, de resto muito representado em todo 
oriente antigo, por outras fontes e narrativas, da "árvore da vida".

Mircea Eliade, tratando do assunto, afirmou que a árvore, nas religiões, representa "pela sua simples presença ('o poder') e pela lei da sua própria evolução ('a regeneração') ... o cosmo inteiro" (ELIADE, 1992, p. 340). Assim, continua, a árvore expressa,

[Q]uer de maneira ritual e concreta, quer de modo mítico e cosmológico, ou ainda puramente simbólico - o cosmos vivo, regenerando-se incessantemente. Sendo a vida inesgotável um equivalente da imortalidade, a árvore-cosmos pode, por esse fato, tornar-se a outro nível, na árvore da 'vida sem morte' (ELIADE, 1992, p. 338).

Mircea Eliade entendia que, por si, a árvore traduzia a experiência da eternidade, ou da renovação continua do mundo. Por isso, talvez, "Lembra-te do teu criador" (...) "quando a amendoeira está em flor" (Ec. 12.5). Pois também o ser humano é flor e fruto de um processo maior de permanente criação de vida. Eliade também distinguiu alguns tipos de exteriorização dessa impressão. Entendeu o historiador romeno que a experiência religiosa do arquétipo da árvore da vida podia ser classificada de diferentes maneiras. Ela podia ser a da "árvore-imagem do cosmos", a da "árvore símbolo da vida, da fecundidade inesgotável, da realidade absoluta" ou a "árvore centro do mundo e suporte do universo" (ELIADE, 1992, p. 337).

Como já pudemos observar, a menorá reúne todas essas dimensões. Sintetiza o cosmo, representa a criação permanente, e evoca a divindade que sustenta o universo. O que a torna, portanto, uma representação da "árvore da vida".

\section{5.}

A "árvore da vida" é, em princípio, na tradição judaica, uma árvore mítica, plantada por Deus no Jardim do Éden. Seu fruto, assim explicado, é fonte de vida eterna, elemento que torna possível ao homem a vivência da eternidade (Gen. 3.22).
A visão bíblica dessa criatura sempre viva, e representação da vida eterna, é abstrata e direcionada para o seu entendimento como "arvore-imagem do cosmos", "árvore símbolo da realidade absoluta" e "árvore centro do mundo e suporte do universo". Assim, na literatura profética, Ezequiel trata o tema numa dimensão messiânica, mas nessas três perspectivas:

Tomarei do cimo do cedro, da extremidade dos seus ramos um broto, e plantá-lo-ei sobre o alto monte de Israel. Ele deitará ramos e produzirá frutos, tornando-se cedro magnífico, de modo que à sua sombra habitará toda espécie de pássaros, à sombra de seus ramos habitará toda a sorte de aves. E saberão todas as árvores do campo que eu, Deus, é que abaixo a árvore alta e exalto a árvore baixa, que seco a árvore verde e faço brotar a árvore seca. Sim, eu, Deus, o disse e o faço (Ez. 17.22-24).

Por conta dessa árvore, saberão "todas as árvores", isto é, todas as formas de vida, que Deus é o senhor do universo, sua fonte. O construtor do equilíbrio cósmico (que abaixa o alto e exalta o baixo) é, nessa figura, também uma fonte inesgotável de realidades, que congrega em si toda vida (todos os pássaros). É imagem, símbolo e suporte. Essa árvore mítica apresenta, portanto, o conhecimento necessário da realidade e potência de Deus, no sentido evidente de anunciar a redenção humana. E por isso é imagem messiânica, como o foram as duas oliveiras de Jeremias.

O tema (conhecimento-árvore cósmica) também aparece na literatura sapiencial: A sabedoria "é a árvore da vida para os que a colhem" (Pr. 3.18) ou "o fruto do justo é a árvore da vida; o sábio recolhe a vida" (Pr.11.30). E, mais claramente, no Eclesiástico: "o conhecimento dos mandamentos do Senhor é a disciplina da vida, os que fazem o que lhe agrada colherão os frutos da arvore da imortalidade". (Eclo. 19.19). O conhecimento do sentido oculto no visível da árvore sagrada abre o caminho para que seu fruto, negado a Adão, "que ele não estenda a mão e colha também da árvore da vida, e coma e viva para sempre" (Gen. 3.22), possa ser comido pelos sábios, ou pelos justos, sinalizando, portanto, a redenção humana. Basicamente, sua imortalidade. 
Mas isso também está relacionado com "o conhecimento dos mandamentos do Senhor", isto é, com a própria Torá, num sentido estrito, o Pentateuco de Moisés, e com a Bíblia num sentido maior.

Segundo Gershom Scholem, o rabino Moses de Leon (c. 1240 - 1305) escreveu que a Torá,

[É] chamada a Árvore da Vida... pois assim como uma árvore consiste de ramos e folhas, casca, seiva e raízes, cada um desses componentes daquilo que se chama uma árvore, e não há diferença substancial entre esses componentes, assim também a Torá possui muitas coisas internas e aparentes, e todas formam uma Torá e uma árvore, sem diferenças entre elas (apud SCHOLEM, 1965, p. 46).

A relação entre a Árvore da Vida, a Torá e Deus pode ser também descoberta num outro tratado cabalista medieval, o Bahir, estudado igualmente por Scholem. Ali é dito que "todos os divinos poderes do Sagrado, abençoado Ele seja, repousam um sobre o outro, e são como uma árvore" (apud SCHOLEM, 1978, p. 106). "As almas", explica Scholem em outra oportunidade, "procedem dessa árvore cósmica e de fato são seus frutos" (SCHOLEM, 1987, p. 72). O que reafirma que a menorea representa a potencial imortalidade do ser, a essencialidade de seus elos com Deus e os firmes elos de associação entre os mundos visível e invisível.

A doutrina dos "divinos poderes" organizados "como uma árvore" adquiriu forma na Kabalá, na estrutura da árvore sefirótica. Ela é entendida a partir de um fluxo contínuo de emanações criadoras, a partir de Deus, Ayin sof, sem fim, e através de dez sefirot, ou atributos divinos, começando em Kether, a "Coroa", e seguindo por Hochmá, a sabedoria, Biná, o "entendimento", Hesed, a "misericórdia", Gevura, a "severidade", Tiferet, a "beleza", Hod, a "reverberação" Yesod o "fundamento" e terminando em Malkut, o "reino". Tudo e todas as coisas conteriam tal estrutura.

Ainda segundo Scholem, foi o Rabbi Asher Ben David quem, em meados do século XIII, difundiu a concepção de entender as sete sefirot inferiores como a menorá, ou "como um cacho de uvas" (SCHOLEM, 1987, p. 393). Assim, no Zohar, é discutido o complexo fluxo de emanações na menorá, e como por ele se pode entender como o universo funciona (Zohar, 11.573-593).

O desenvolvimento místico do significado da menorá, enquanto "arvore da vida", ou "árvore cósmica", atingiu assim dimensões maiores e profundas do entendimento da realidade. A determinação divina: "Farás um candelabro de ouro puro" (Ex 25.31) tornou-se uma mitsvá, uma determinação não restrita apenas ao ritual, mas estendida ao entendimento abstrato do significado maior de algo que pode parecer uma amendoeira estilizada, mas que é, em seu interior, um plano do universo, a ser continuamente reproduzido, no sentido da busca da redenção e da eternidade.

6.

Uma lenda judaica conta que quando Deus pediu a Moisés que construísse a menorá, "ele considerou isso muito difícil, pois não sabia como fazê-la em todos seus complicados detalhes". Deus então disse a Moisés: "Eu vou the mostrar um modelo". Então Deus pegou um fogo branco, um fogo vermeIho, um fogo verde e um fogo negro e com esses quatro tipos de fogos ele construiu um candelabro "como todos seus cálices, botões e flores". Mas, mesmo assim, Moisés foi incapaz de fazer uma cópia do candelabro. E, portanto, Deus a desenhou na palma de sua mão, e disse: "Olhe isto e imita o desenho que eu fiz na sua palma" (GINZBERG, 2003, p. 678).

Neste midrash está apontado que o segredo da menorá está, em princípio, nas linhas da mão. Tão individuais e tão universalmente misteriosas e que lembram, de fato, uma menorá. Mas tal menorá, tendo um sentido tão abstrato, distante e difícil, está presente, como Árvore da Vida, tanto na essência quanto na aparência, tanto no invisível quanto na realidade visível dos homens. Experiência transcendente e íntima. Testifica a presença do Todo na parte.

Assim, de uma narrativa fundadora, no Êxodo, que expressava a transcendência absoluta de Deus, o desenvolvimento da literatura bíblica alcançou, 
através da representação arquetípica da menorá, a percepção da existência de uma árvore cósmica, que viceja no paraíso, no universo, na natureza e no interior, ou na palma da mão, humana.

\section{THE MENORAH AND THE TREE OF LIFE}

Abstract: The menorah, the seven-branched candelabrum, a ritual object of the Jerusalem Temple, acquired great relevance in biblical literature. First, as a representation of the cosmos, both the visible and invisible world. Second, as the tree of life, and representation of God and eternal life. Finally, in Kabbalah, as a representation of sefirotic tree.

Keywords: Menorah, Judaism, Tree of Life

\section{REFERÊNCIAS BIBLIOGRÁFICAS}

\section{Fontes}

Todos os textos bíblicos citados o foram da Bíblia de Jerusalém. São Paulo, Paulus, 2004. Cotejado, eventualmente, com o texto hebraico da Bíblia Hebraica Stuttgartensia, Hendrickson, 2006.

\section{Bibliografia:}

ELIADE, Mircea. Tratado de História das Religiões. Porto: ASA, 1992.

GINZBERG, Louis. Legends of the Jews. Vols. I and II [1909] Philadelphia: Jewish Publication Society, 2003.

HACHLILI, Rachel. The Menorah, The Ancient SevenArmed Candelabrum. Origin, Form and Significance. Leiden: Brill, 2001.

MEYERS, Carol. Lampstand. In: FREEDMAN, David (ed.) Anchor, Bible Dictionary. Doubleday, 1992.

PHILO. Vol. VI. On Moses. Transl. by COLSON, F.H. London, Loeb Classical Library, 1985.

RABINOWITZ, L. I. Luz of the Spine. in SKOLNIK, Fred (ed.). Encyclopedia Judaica Vol. XIII. Detroit: Thomson Gale, 2007.

SCHMIDT, M. The Tabernacle of Exodus as a Work of Art. London: Edwin Mellen Press, 2009.

SCHOLEM, G. On the Kabbalah and its Symbolism. New York: Schocken Books, 1965.
SCHOLEM, G. Origins of The Kabbalah. Princeton: Princeton University Press, 1987.

SCHOLEM, G. Kabbalah. New York: Meridian, 1978.

SHIMOM BAR-YOCHAI (translation by BERG, Michael). The Zohar. Los Angeles: The Kabbalah Center International Inc., 2003.

YARDEN, L. The Spoils of Jerusalem on the Arch of Titus: a Reinvestigation. Acta Instituti Romani Regni Sueciae, Skrifter Utgivna av Svenska Institutet i Rom, 8.16. Stockholm: Paul Åströms, 1991. 